\title{
Accessing Sodium Ferrate Complexes Containing Neutral and Anionic N- Heterocyclic Carbene Ligands: Structural, Synthetic and Magnetic Insights
}

Lewis C. H. Maddock, ${ }^{a}$ Thomas Cadenbach, ${ }^{a}$ Alan R. Kennedy, ${ }^{a}$ Ivana Borilovic, ${ }^{b}$ Guillem Aromí ${ }^{\mathrm{b}}$ and Eva Hevia*a

${ }^{a}$ WestCHEM, Department of Pure and Applied Chemistry, University of Strathclyde, Glasgow, UK, G1 $1 X L$

${ }^{b}$ Departament de Química Inorgànica, Universitat de Barcelona, Diagonal 645, 08028 Barcelona, Spain

\section{Abstract}

This study reports the synthesis, single crystal X-ray crystallographic, NMR spectroscopic and magnetic characterization of a series of sodium ferrates using bis(amide) Fe(HMDS) $)_{2}$ as a precursor $(\mathrm{HMDS}=1,1,1,3,3,3$-hexamethyldisilazide). Reaction with sodium reagents NaHMDS and $\mathrm{NaCH}_{2} \mathrm{SiMe}_{3}$ in hexane afforded donor-solvent free sodium ferrates $\left[\left\{\mathrm{NaFe}(\mathrm{HMDS})_{3}\right\}_{\infty}\right](\mathbf{1})$ and $\left[\left\{\mathrm{NaFe}(\mathrm{HMDS})_{2}\left(\mathrm{CH}_{2} \mathrm{SiMe}_{3}\right)\right\}_{\infty}\right]$ (2) respectively which exhibit contacted ion pair structures, giving rise to new polymeric chain arrangements made up of a combination of inter and intramolecular $\mathrm{Na} \cdots \mathrm{Me}(\mathrm{HMDS})$ electrostatic interactions. Addition of the unsaturated NHC IPr (IPr = 1,3-bis-(2,6-diisopropylphenyl)imidazol-2-ylidene) to $\mathbf{1}$ and 2 caused deaggregation of their polymeric structures to form discrete NHC-stabilized solvent-separated ion pairs $\quad\left[\mathrm{Na}(\operatorname{IPr})_{2}\right]^{+}\left[\mathrm{Fe}(\mathrm{HMDS})_{3}\right]^{-} \quad$ (3) and $\left[(\mathrm{THF})_{3} \cdot \mathrm{NaIPr}\right]^{+}\left[\mathrm{Fe}(\mathrm{HMDS})_{2} \mathrm{CH}_{2} \mathrm{SiMe}_{3}\right]^{-}$(4), where in both cases, the NHC ligand coordinates preferentially to Na. Contrastingly, when IPr is sequentially reacted with the single-metal reagents $\mathrm{NaCH}_{2} \mathrm{SiMe}_{3}$ and $\mathrm{Fe}(\mathrm{HMDS})_{2}$, novel heteroleptic ferrate (THF) $)_{3} \mathrm{Na}\left[: \mathrm{C}\left\{\left[\mathrm{N}\left(2,6-{ }^{\mathrm{i}} \mathrm{Pr}_{2} \mathrm{C}_{6} \mathrm{H}_{3}\right)\right]_{2} \mathrm{CHCFe}(\mathrm{HMDS})_{2}\right\}\right]$ (5) is obtained. This contains an anionic NHC ligand acting as an unsymmetrical bridge between the two metals, coordinating through its abnormal $\mathrm{C} 4$ position to $\mathrm{Fe}$ and its normal $\mathrm{C} 2$ position to $\mathrm{Na}$. The formation of $\mathbf{5}$ can be described as an indirect ferration process where IPr is first metallated at C4 position by the polar sodium alkyl reagent which in turn undergoes transmetallation to the more electronegative $\mathrm{Fe}(\mathrm{HMDS})_{2}$ fragment. Treatment of $\mathbf{5}$ with one molar equivalent of methyltriflate (MeOTf) led to the isolation and structural elucidation of neutral abnormal NHC (aNHC) tricoordinate iron complex $\left[\mathrm{CH}_{3} \mathrm{C}\left\{\left[\mathrm{N}\left(2,6-\mathrm{iPr}_{2} \mathrm{C}_{6} \mathrm{H}_{3}\right)\right]_{2} \mathrm{CHCFe}(\mathrm{HMDS})_{2}\right\}\right]$ (6) with the subsequent elimination of NaOTf, disclosing the selectivity of complex 5 to react 
with this electrophile via its $\mathrm{C} 2$ position, leaving its $\mathrm{Fe}-\mathrm{C} 4$ and $\mathrm{Fe}-\mathrm{N}$ bonds intact. The magnetic susceptibility properties of compounds 1-6 have been examined. This study revealed a drastic change of magnetic susceptibility in replacing a pure $\sigma$-donor from an idealized trigonal coordination environment by an $\mathrm{NHC} \pi$ donating character.

\section{Introduction}

Over the past decade the chemistry of $s$-block heterobimetallic (ate) reagents, which combine metals of markedly different polarities has developed at a remarkable pace, with the realization of their synergic chemical profiles, which cannot be replicated by their singlemetal components. ${ }^{1}$ Switching on cooperative effects, these ates, usually made by pairing an alkali-metal with either $\mathrm{Mg}$ or $\mathrm{Zn}$, can display enhanced reactivities, unique selectivities and superior functional group tolerance to traditional polar organometallic reagents such as organolithium and Grignard reagents. ${ }^{2}$ Finding widespread applications in a myriad of organic transformations, some of these multicomponent systems have emerged as versatile and potent deprotonating reagents, allowing direct magnesiation or zincation of a wide range of aromatic substrates. ${ }^{3}$ Isolation of key organometallic intermediates involved in these transformations has provided new insights into how these bimetallic systems operate as recently shown for the unprecedented meta-meta' dimagnesiation of $N, N$-dimethylaniline where the supramolecular structure of the mixed-metal base templates the regioselectivity of the deprotonation process. ${ }^{4}$ Extension of some of these studies to transition metal systems, replacing the low polarity $s$-block metal by another divalent metal such as $\mathrm{Mn}$ (II), $\mathrm{Cr}$ (II) or Fe(II) have already hinted at the potential of these systems to display related synergic chemistry. ${ }^{5}$ Focusing on Fe(II) ferrate complexes, direct ferration of substituted aromatic substrates has been reported using mixed lithium-iron bases which contain the bulky amide group TMP (TMP=2,2,6,6-tetramethylpiperidide). ${ }^{6,7}$ Interestingly in some cases the in situ generated functionalized aryl ferrate intermediates can subsequently undergo Ni-catalyzed cross-coupling reactions with organic halides. ${ }^{6}$ In closely related work, Mulvey has shown that structurally defined sodium ferrate [(TMEDA) NaFe(TMP) $\left.\left(\mathrm{CH}_{2} \mathrm{SiMe}_{3}\right)_{2}\right](\mathrm{TMEDA}=$ $N, N, N^{\prime}, N$ '-tetramethylethylenediamine) promotes the regioselective two-fold ferration of benzene at the sterically-optimal 1- and 4-positions affording a unique iron-host inversecrown complex. $^{5 a}$ More recently Bedford has elegantly disclosed the key involvement of homoleptic aryl ferrates in iron-catalyzed Kumada coupling processes. ${ }^{8}$ Surprisingly, despite their synthetic relevance and the increasing attention that organoiron chemistry is currently being paid, ${ }^{9}$ the number of structurally defined alkali-metal ferrates still remains scarce. ${ }^{10}$ 
Running in parallel to this research has been that of iron complexes containing $N$-heterocyclic carbene ligands (NHC's), ${ }^{11}$ which have found numerous applications in catalytic transformations, including $\mathrm{C}-\mathrm{C}$ and $\mathrm{C}-\mathrm{N}$ bond formation processes. ${ }^{12}$ Although in many cases the nature of the active iron species implicated in these transformations has not been made forthcoming, the involvement of low-coordinate Fe NHC-complexes has been postulated, ${ }^{13}$ which have sparked widespread interest in the synthesis and reactivity of this particular type of compound. ${ }^{11,14}$

Merging these two evolving fields in synthesis, namely cooperative bimetallics and NHC-Fe chemistry, together, here we report our findings on the synthesis of a new series of NHCstabilized sodium ferrates containing the unsaturated carbene $\operatorname{IPr}(\mathbf{I P r}=1,3$-bis-(2,6diisopropylphenyl)imidazol-2-ylidene). Combining X-ray crystallography and spectroscopic studies with SQUID magnetization investigations, we assess the constitution and reactivity of this family of complexes, unveiling a method that grants access to a three-coordinate abnormal-NHC Fe complex.

\section{Results and Discussion}

Synthesis of donor-solvent-free sodium ferrates. Building on our previous studies on the synthesis of alkali-metal magnesiate and zincate complexes, ${ }^{15,16}$ we started our investigation assessing the co-complexation reaction between $\mathrm{Fe}(\mathrm{II})$ amide $\mathrm{Fe}(\mathrm{HMDS})_{2}$ (HMDS = 1,1,1,3,3,3-hexamethyldisilazide, $\left.\mathrm{N}\left(\mathrm{SiMe}_{3}\right)_{2}\right)^{17}$ and the sodium amide NaHMDS or the monosilyl derivative $\mathrm{NaCH}_{2} \mathrm{SiMe}_{3}{ }^{18}$ in the non-coordinating solvent hexane. Although both sodium compounds are sparingly soluble in hexane, addition of the Fe bis(amide) and gentle heating afforded dark green homogeneous solutions, that deposited green crystals of homoleptic and heteroleptic donor-solvent-free sodium ferrates [ $\left.\left\{\mathrm{NaFe}(\mathrm{HMDS})_{3}\right\}_{\infty}\right](\mathbf{1})$ and $\left[\left\{\mathrm{NaFe}(\mathrm{HMDS})_{2}\left(\mathrm{CH}_{2} \mathrm{SiMe}_{3}\right)\right\}_{\infty}\right](2)$ in an $80 \%$ and $73 \%$ yield respectively (Scheme 1).

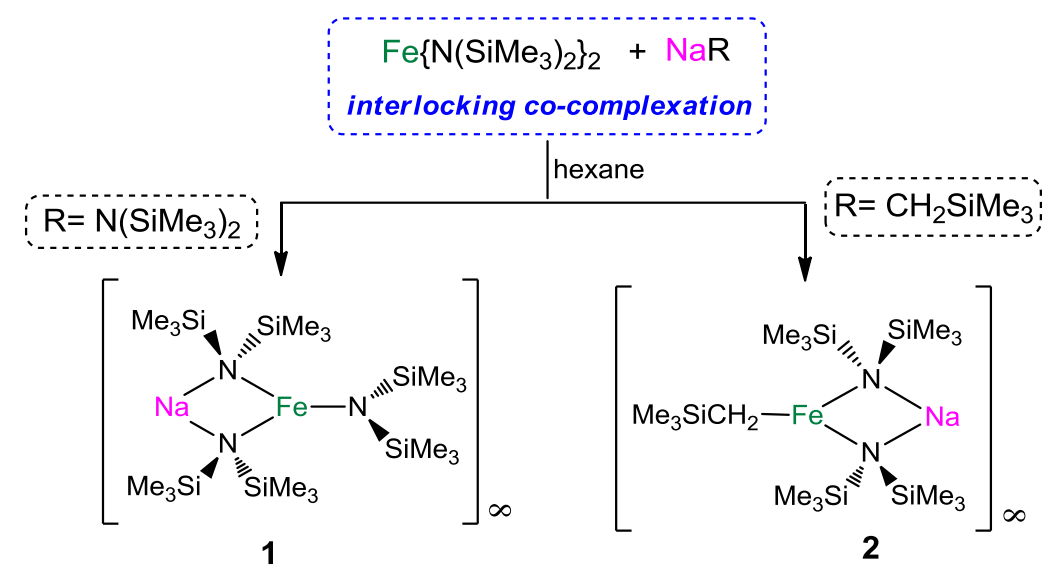

Scheme 1 Synthesis of donor-solvent-free sodium ferrates 1 and 2. 
As determined by X-ray crystallography, the structures of contacted ion-pair ferrates $\mathbf{1}$ and $\mathbf{2}$ were found to be based on a planar four-membered $\{\mathrm{NaNFeN}\}$ ring (Figures 1a and $2 \mathrm{a}$ respectively), where both metals are connected by two HMDS bridges, while the remaining anionic ligand (HMDS or $\mathrm{CH}_{2} \mathrm{SiMe}_{3}$ for $\mathbf{1}$ and $\mathbf{2}$ respectively) occupies a third (terminal) coordination site on Fe. Coordinatively unsaturated within these asymmetric units, the solvent-free sodium centers in $\mathbf{1}$ and $\mathbf{2}$ attain higher coordination numbers by forming intermolecular interactions with the HMDS groups of adjacent molecular units (via $\mathrm{Na} \cdots \mathrm{Me}$ electrostatic contacts), which afford in both cases new 1D polymeric chain structures (Figures $1 \mathrm{~b}$ and $2 \mathrm{~b}$ respectively). Thus, for $\mathbf{1}$ each $\mathrm{Na}$ interacts with a single Me group from the terminal HMDS ligand of a neighboring $\left\{\mathrm{NaFe}(\mathrm{HMDS})_{3}\right\}$ fragment $[\mathrm{Na}(1)-\mathrm{C} 18,2.838(4) \AA]$, giving rise to a linear head-to-tail arrangement (Figure 1b). This motif is in marked contrast to the discrete monomeric structure recently reported for the lithium analog of $\mathbf{1}$, $\left[\mathrm{LiFe}(\mathrm{HMDS})_{3}\right],{ }^{10 \mathrm{~g}}$ where Li attains a tetrahedral geometry by forming two intramolecular Li $\cdots \mathrm{Me}(\mathrm{HMDS})$ contacts. ${ }^{19}$ Donor-free alkali-metal ate structures are rare in heterobimetallic chemistry, ${ }^{20}$ and as far as we are aware, the structure of $\mathbf{1}$ along with that of the lithium ferrate above mentioned, constitute the first examples of homoleptic HMDS-based ates containing a divalent transition metal. ${ }^{21}$ Understandably, the mean Fe-N bond length for the bridging HMDS ligands in $\mathbf{1}$ [2.034 $\AA$ ] is slightly elongated compared to the terminal Fe1-N3 $[1.964(2) \AA]$. These values are in good agreement to those reported for THF adduct $\left[(\mathrm{THF}) \mathrm{NaFe}(\mathrm{HMDS})_{3}\right],{ }^{22}$ which also exhibits a contacted ion-pair structure, with a threecoordinated distorted trigonal planar Fe(II) center, ${ }^{23}$ and they show very little variation to those found in the solvent-free lithium ferrate mentioned above ${ }^{10 \mathrm{~g}}$ or in the neutral iron bis(amide) $\left[\left\{\mathrm{Fe}(\mathrm{HMDS})_{2}\right\}_{2}\right]$ (mean values of 2.084 and $1.925 \AA$ for bridging and terminal Fe$\mathrm{N}$ distances respectively). ${ }^{17 \mathrm{~b}}$ Interestingly, this THF-solvate has been prepared using an alternative synthetic method to that described for $\mathbf{1}$, by reducing Fe(III) amide Fe(HMDS) 3 with the sodium silanide $(\mathrm{THF})_{2} \mathrm{Na}\left(\mathrm{Si} t \mathrm{Bu}_{3}\right)$ and co-formation of disilane $t \mathrm{Bu}_{3} \mathrm{Si}-\mathrm{Si} t \mathrm{Bu}_{3}{ }^{22}$ Having a mean value of $2.497 \AA$, the Na-N distances in $\mathbf{1}$ show a noticeable variation from those in sodium dimeric complex $\left[\left\{(t \mathrm{BuCN})_{2} \mathrm{Na}(\mathrm{HMDS})\right\}_{2}\right][2.405 \AA],{ }^{23}$ where the $\mathrm{Na}$ centres are also tricoordinated although in this case the $\mathrm{NNaN}$ bond angle is significantly more obtuse than in $\mathbf{1}\left[100.3(1)\right.$ vs $\left.84.03(9)^{\circ}\right] .{ }^{25}$ These structural features can be rationalised considering the different nature of the metal-N bonds present in this heterobimetallic species. Thus, the shorter and more covalent anchoring Fe-N bonds provide the foundations for the 
$\left\{\mathrm{Fe}(\mathrm{HMDS})_{3}\right\}^{-}$units to which the sodium cations are affixed by a combination of weaker $\mathrm{Na}-\mathrm{N}$ and $\mathrm{Na} \cdots \mathrm{CH}_{3}$ ancillary bonds. ${ }^{26}$

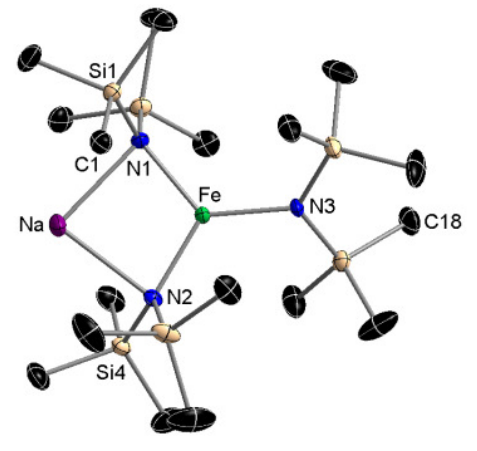

(a)

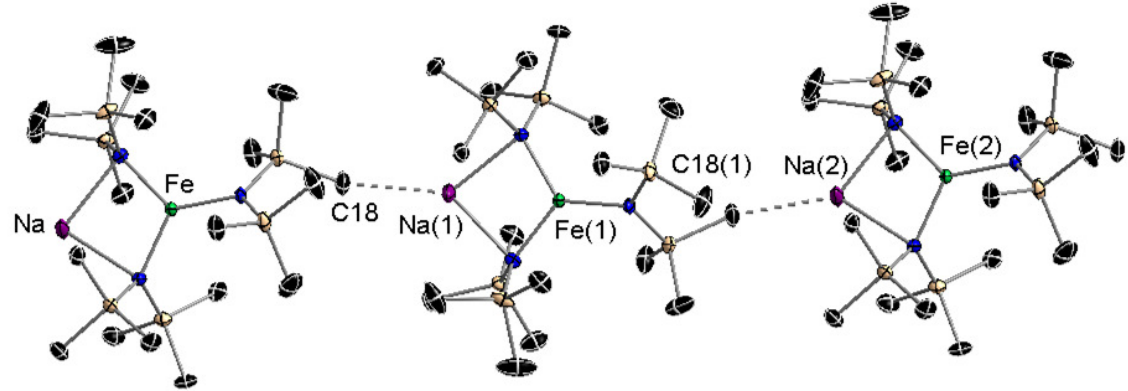

(b)

Figure 1: (a) Asymmetric unit of $\left[\left\{\mathrm{NaFe}(\mathrm{HMDS})_{3}\right\}_{\infty}\right]$ (1). Hydrogen atoms omitted for clarity. Thermal ellipsoids displayed at $50 \%$ probability level. Selected bond distances $(\AA)$ and angles $\left(^{\circ}\right)$ : Fe-N1 2.036(2), Fe-N2 2.032(2), Fe-N3 1.964(2), Fe' Na 3.0131(13), Na-N1 2.502(3), Na-N2 2.492(3); N1-Fe-N2 110.48(10), N1-Fe-N3 124.93(10), N2-Fe-N3 124.56(10), Na-N1-Fe 82.51(8), Na-N2-Fe 82.86(8), Na-Fe-N3 176.00(9), N1-Na-N2 $84.03(9)$. (b) Section of polymeric chain showing propagation and selected atom labelling, $\mathrm{Na}(1)-\mathrm{C} 182.838(4) \AA$

Contrasting with the linear arrangement of $\mathbf{1}$, heteroleptic sodium ferrate $\mathbf{2}$ exists as a zig-zag chain polymer (Figure $2 b$ ) comprising $\left\{\mathrm{NaFe}(\mathrm{HMDS}) \mathrm{CH}_{2} \mathrm{SiMe}_{3}\right\}$ units connected in a headto-head arrangement via $\mathrm{Na}$...Me(HMDS) medium-long electrostatic interactions [ $\mathrm{Na}(1)-\mathrm{C} 2$ 2.854(2), Na1-C12(2) 3.041(2) $\AA$ ] with the terminal alkyl groups attached to the Fe atoms and running along opposite edges of the chain in a staggered fashion. Illustrating the structural similarities of $\mathrm{Mn}(\mathrm{II})$ and $\mathrm{Fe}(\mathrm{II})$ in heterobimetallic chemistry, this motif is almost identical to that described by Mulvey and Klett for $\left[\mathrm{NaMn}(\mathrm{HMDS})_{2} \mathrm{CH}_{2} \mathrm{SiMe}_{3}\right] .{ }^{27,}{ }^{28}$ The propagation mode in 2, exclusively involving $\mathrm{Na} \cdots \mathrm{Me}$ bonds, contrasts with that found in the related magnesiate $\left[\left\{\mathrm{NaMg}(\mathrm{HMDS})_{2} \mathrm{Bu}\right\}_{\infty}\right]$, which polymerises via the anionic $\mathrm{C}$ of the butyl group giving rise to a linear chain. ${ }^{20 \mathrm{c}}$ Contrastingly in $\mathbf{2}$ the monosilyl group binds terminally to $\mathrm{Fe}$ $[\mathrm{Fe}-\mathrm{C} 13$ 2.051(2) $\AA] .{ }^{28}$ The main geometrical parameters within the dinuclear $\{\mathrm{NaNFeN}\}$ ring show little variation to those discussed for $\mathbf{1}$, although in $\mathbf{2}$ the sodium atom receives additional stabilization within the asymmetry unit by forming two intramolecular $\mathrm{Na} \cdots \mathrm{Me}$ contacts [Na-C8, 2.7275(21); Na1-C6, 2.7013(21) $\AA$ ] (Figure 2a), which are noticeably shorter than its propagating intermolecular interactions (vide supra). Thus while the Fe center in $\mathbf{2}$ has a similar distorted trigonal planar geometry to that of $\mathbf{1}$ [sum of the internal angles around $\mathrm{Fe}$ is $359.97^{\circ}$, ranging from $107.96(10)$ to $\left.129.08(10)^{\circ}\right]$, the sodium atoms in 2 reach 
hexacoordination by bonding to two N's and four Me(HMDS) groups (while in $1 \mathrm{Na}$ exists in a tricoordinate environment).

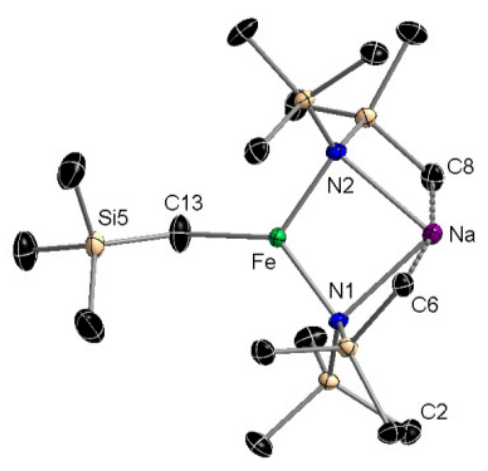

(a)

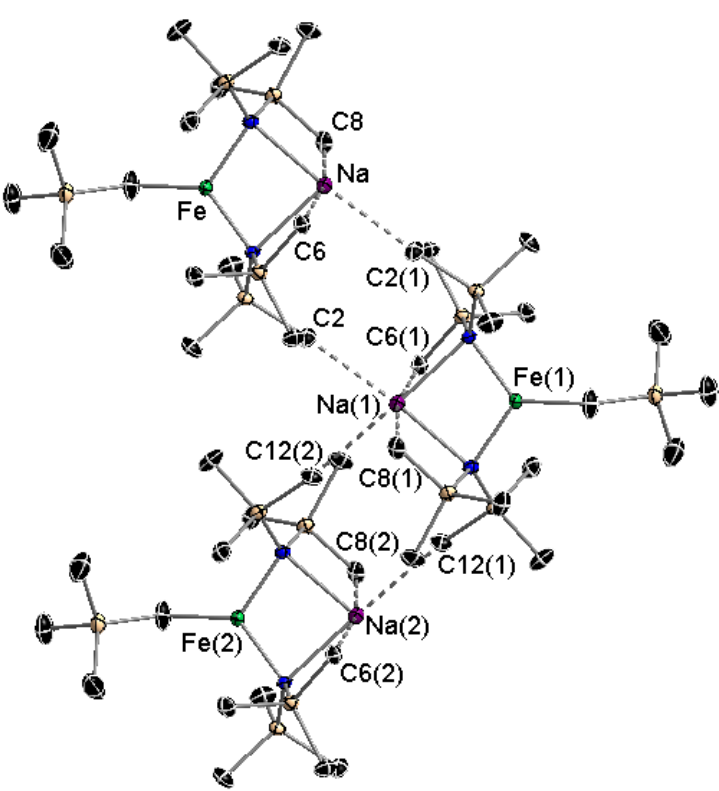

(b)

Figure 2: (a) Asymmetric unit of $\left[\left\{\mathrm{NaFe}(\mathrm{HMDS})_{2}\left(\mathrm{CH}_{2} \mathrm{SiMe}_{3}\right)\right\}_{\infty}\right]$ (2). Hydrogen atoms omitted for clarity. Thermal ellipsoids displayed at $50 \%$ probability level. Selected bond distances $(\AA)$ and angles $\left({ }^{\circ}\right)$ : Fe-N1 2.0308(17), Fe-N2 2.0306(17), Fe-C13 2.051(2), Na-C6 2.7013(21), Na-C8 2.7275(21), Fe' Na 3.0401(9), Na-N1 2.4804(19), Na-N2 2.4702(19), N1Fe-N2 107.96(7), N1-Fe-C13 129.08(10), N2-Fe-C13 121.83(10), Na-N1-Fe 84.11(6), NaN2-Fe 84.38(6), Na-Fe-C13 165.55(7), N1-Na-N2 83.14(6). (b) Section of polymeric chain showing intermolecular and intramolecular Na-Me contacts $\mathrm{Na}(1)-\mathrm{C} 2$ 2.838(4) $\AA, \mathrm{Na}(1)-$ C12(2) 3.041(2) $\AA$.

Both, compounds 1 and 2, exhibit good solubility in $\mathrm{C}_{6} \mathrm{D}_{6}$, suggesting that their polymeric structures observed in the solid state are not retained in solution. The paramagnetic character of these heterobimetallic compounds is manifested in the broad paramagnetically shifted resonances observed in their ${ }^{1} \mathrm{H}$ and ${ }^{13} \mathrm{C}$ NMR spectra. Reflecting the ferrate constitution of $\mathbf{1}$, its ${ }^{1} \mathrm{H}$ NMR spectrum shows a broad signal at $-4.72 \mathrm{ppm}$ for the $\mathrm{SiMe}_{3}$ groups, which is moved drastically upfield from the corresponding resonance found for the $\operatorname{Fe}(\mathrm{HMDS})_{2}$ precursor in the same deuterated solvent (at $60.27 \mathrm{ppm}$ ). The solution-phase magnetic moment of 1 was found to be $4.72 \mu \mathrm{B}$ (determined by the Evans method), ${ }^{30}$ which is close to the expected value $(4.90 \mu \mathrm{B})$ for a high-spin $(S=2) \mathrm{Fe}(\mathrm{II})$ centre. ${ }^{31}$ The ${ }^{1} \mathrm{H}$ NMR spectrum of 2 displayed two distinct $\mathrm{SiMe}_{3}$ resonances easily assignable for the HMDS groups (at -8.57 ppm integrating for $36 \mathrm{H}$ ) and for the monosilyl ligand (at $13.51 \mathrm{ppm}$ integrating for $9 \mathrm{H}$ ) (see Supporting Information for details). ${ }^{32-33}$ 
Reactivity studies using the NHC, IPr. Next we investigated the reactivity of sodium ferrates with unsaturated NHC IPr, finding that treating hexane solutions of each bimetallic compound with equimolar amounts of this carbene led to a significant color change (from green to light brown) and the formation of insoluble products. Addition of fluorobenzene in the case of $\mathbf{1}$ and THF for $\mathbf{2}$ afforded crystals of the NHC-stabilized sodium ferrates $\left[\mathrm{Na}(\mathrm{IPr})_{2}\right]^{+}\left[\mathrm{Fe}(\mathrm{HMDS})_{3}\right]^{-}(\mathbf{3})$ and $\left[(\mathrm{THF})_{3} \bullet \mathrm{NaIPr}\right]^{+}\left[\mathrm{Fe}(\mathrm{HMDS})_{2} \mathrm{CH}_{2} \mathrm{SiMe}_{3}\right]^{-}$(4) respectively, in a 35 and $70 \%$ yield (note that the yield of 3 can rise to $73 \%$ by employing two equivalents of IPr) (Scheme 2a-b).

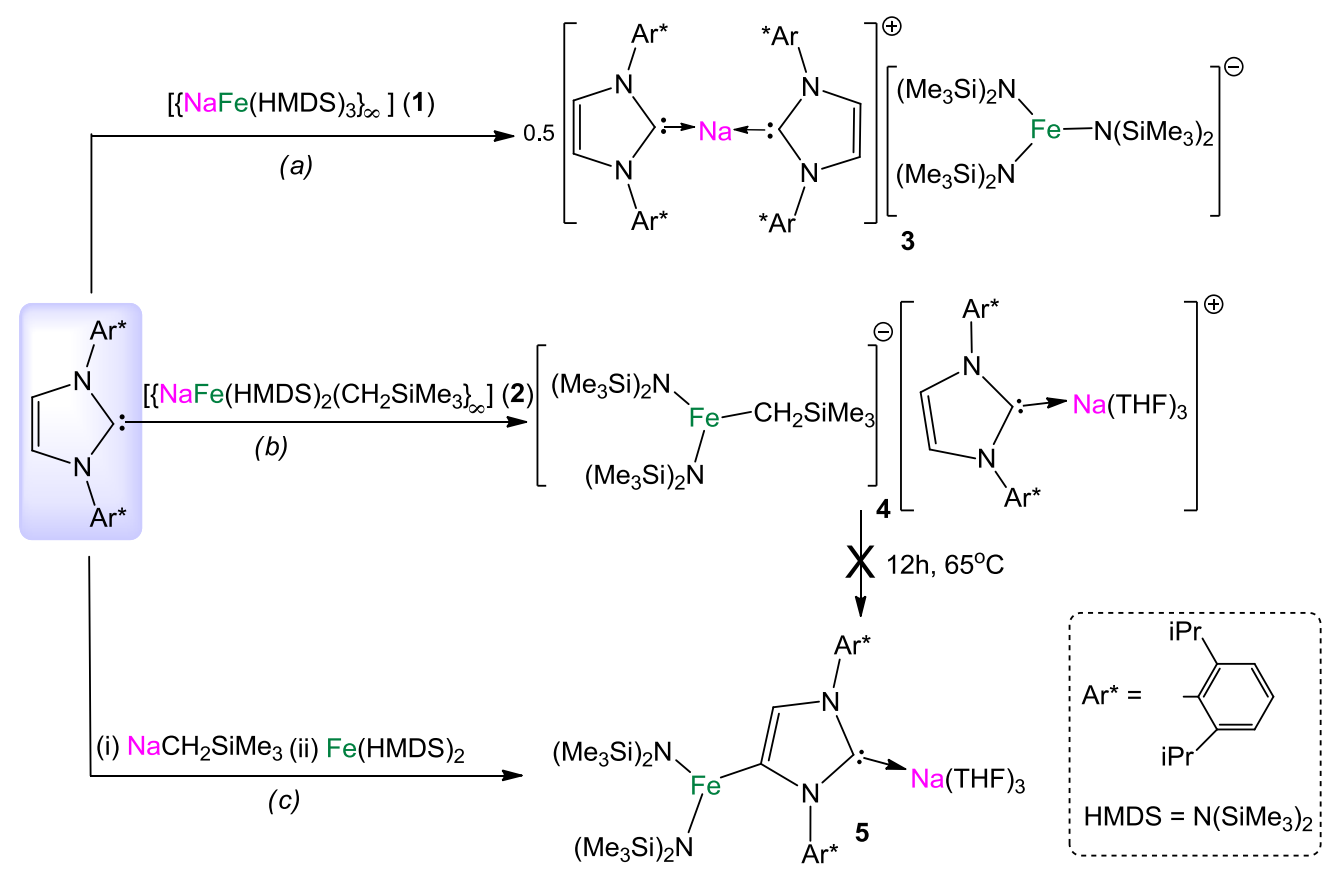

Scheme 2 - Synthesis of NHC-stabilized sodium ferrates: (a) 3; (b) $\mathbf{4}$ and (c) heteroleptic ferrate $\mathbf{5}$ via an indirect ferration approach.

X-ray crystallographic studies established the molecular structures of 3 and 4 . In each case the infinite polymeric arrangement of sodium ferrates $\mathbf{1}$ or $\mathbf{2}$ have deaggregated to form discrete monomeric solvent-separated ion pair structures where the NHC ligands act as neutral lone-pair donors stabilizing the alkali-metal (Figures 3 and 4). The molecular structure of $\mathbf{3}$ comprises a cationic moiety where the Na centre is solvated by two neutral IPr ligands in a near-linear disposition [C-Na-C bond angle $\left.168.95(17)^{\circ}\right]$ and an anionic ferrate moiety featuring a strictly planar tricoordinate Fe(II) centre ( with a mean Fe-N bond length of $1.993 \AA$. Consistent with its anionic constitution, this Fe-N bond distance is understandably longer compared to that found in the related neutral $\mathrm{Fe}(\mathrm{III})$ 
tris(amide) $\mathrm{Fe}(\mathrm{HMDS})_{3}[1.917(4) \AA]^{34}$ which also exhibits a trigonal planar geometry around Fe. It should be noted that the anion moiety of $\mathbf{3}$ has been previously reported by Dehnicke and co-workers in the structure of $\left[\mathrm{Na}(12 \text {-crown- } 4)_{2}\right]^{+}\left[\mathrm{Fe}(\mathrm{HMDS})_{3}\right]^{-}$, but made in a different way by reduction of the Fe(III) precursor Fe(HMDS) $)_{3}$ with NaHMDS in the presence of the metal sequestering ligand 12-crown-4 ether. ${ }^{35}$ Interestingly, the structure of $\mathbf{3}$ bears a strong resemblance to the sodium magnesiate $\left[\mathrm{Na}(\mathrm{IPr})_{2}\right]^{+}\left[\mathrm{Mg}(\mathrm{HMDS})_{3}\right]^{-}$reported by Hill, ${ }^{36}$ which contains the same cationic moiety, with the $\mathrm{Na}$ and $\mathrm{Mg}$ centers exhibiting an almost identical coordination environment to those described above for $\mathrm{Na}$ and Fe respectively in $\mathbf{3}$.
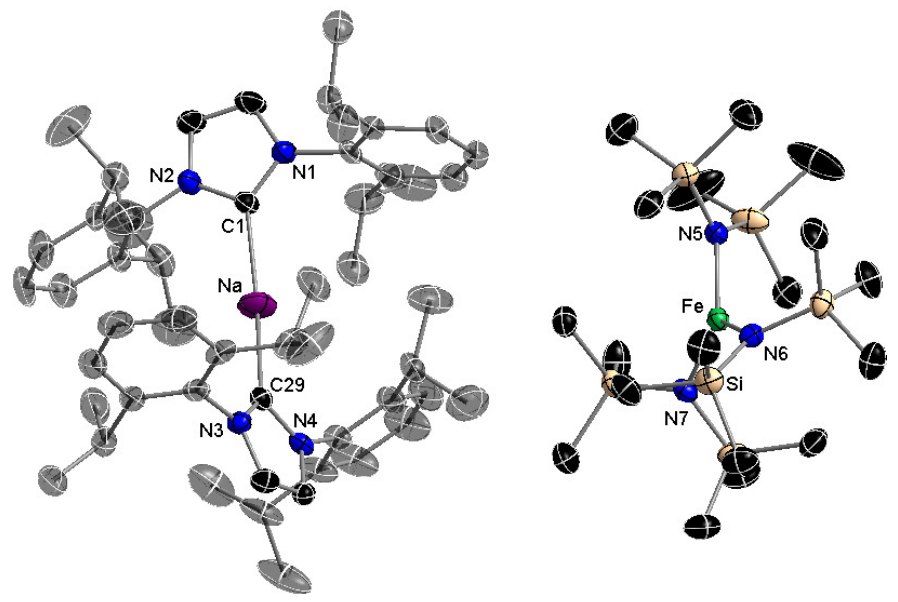

Figure 3: Molecular moieties of the X-ray crystal structure of compound $\left[\mathrm{Na}(\mathrm{IPr})_{2}\right]^{+}\left[\mathrm{Fe}(\mathrm{HMDS})_{3}\right]^{-}$(3) with selective atom labeling. Hydrogen atoms and disorder components in isopropyl groups omitted for clarity. Thermal ellipsoids displayed at $50 \%$ probability level. Selected bond distances $(\AA)$ and angles $\left(^{\circ}\right)$ : Fe-N5 1.996(3), Fe-N6 1.993(3), Fe-N7 1.990(3), Na-C1 2.445(4), Na-C29 2.460(4), C1-N1 1.360(5), C1-N2 1.362(5), C29-N3 1.363(5), C29-N4 1.362(5); N5-Fe-N6 121.15(13), N5-Fe-N7 119.66(13), N6-Fe-N7 119.20(13), C1-Na-C29 168.95(17), Na-C1-N1 137.4(3), Na-C1-N2 120.2(3), N1C1-N2 102.3(3), Na-C29-N3 142.9(3), Na-C29-N4 114.7(3), N3-C29-N4 102.3(3).

Diverging from $\mathbf{3}$, the Na centre in $\mathbf{4}$ binds to only one IPr ligand but completes a distorted tetrahedral geometry by coordinating three molecules of the donor solvent THF [average angle around $\mathrm{Na}, 108.7^{\circ}$, values ranging from $89.5(6)$ to $\left.126.5(6)^{\circ}\right]$. Although the structure of this cation is not known the coordination around $\mathrm{Na}$ is almost identical to that described in the sodium zincate $\left[(\mathrm{THF})_{3} \mathrm{Na}\left[: \mathrm{C}\left\{\left[\mathrm{N}\left(2,6-\mathrm{iPr}_{2} \mathrm{C}_{6} \mathrm{H}_{3}\right)\right]_{2} \mathrm{CHCZn}(t \mathrm{Bu})_{2}\right\}\right]\right.$, which contains an anionic version of the NHC ligand $\operatorname{IPr}^{37}$ which coordinates to a $\left\{\mathrm{Na}(\mathrm{THF})_{3}\right\}$ cation via its $\mathrm{C} 2$ position forming a Na-C bond of 2.501(3) $\AA$ of similar strength to that found in 4 [Na-C2, 2.551(3) $\AA]$. The structure of 4 is completed by the new heteroleptic ferrate anion $\left\{\mathrm{Fe}(\mathrm{HMDS})_{2} \mathrm{CH}_{2} \mathrm{SiMe}_{3}\right\}^{-}$, which as a consequence of its lack of interaction with the $\mathrm{Na}$ center, exhibits a significantly wider NFeN bond angle $\left[123.40(10)^{\circ}\right]$ and slightly shorter Fe- 
$\mathrm{N}$ bond distances $[1.985 \AA]$ than those observed in the contacted ion pair precursor 2 $\left[107.96(7)^{\circ}\right.$ and $\left.2.031 \AA\right]$.
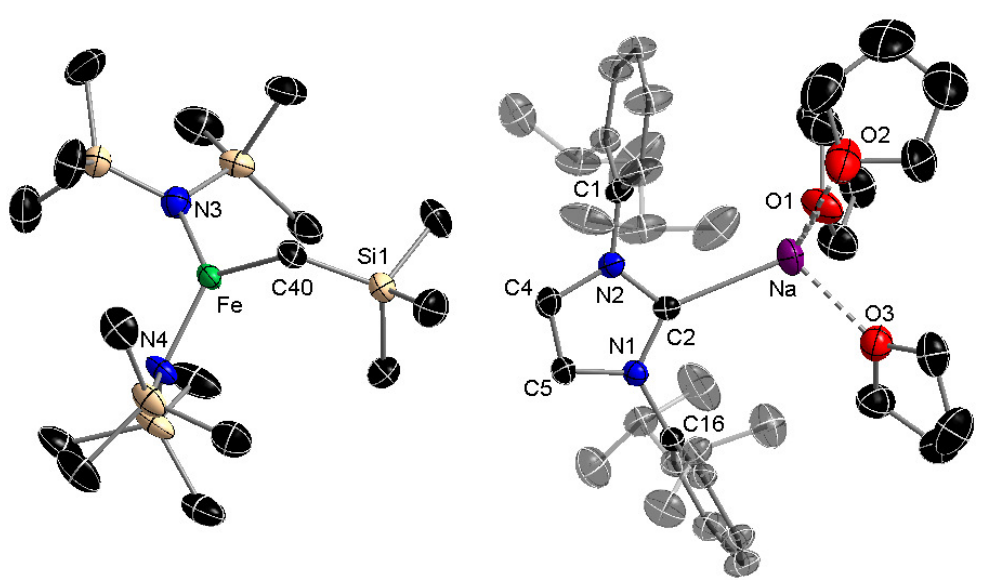

Figure 4: Molecular structure of $\left[(\mathrm{THF})_{3} \cdot \mathrm{NaIPr}\right]^{+}\left[\mathrm{Fe}(\mathrm{HMDS})_{2} \mathrm{CH}_{2} \mathrm{SiMe}_{3}\right]^{-}$(4). Hydrogen atoms and disorder components in isopropyl, THF and $\mathrm{SiMe}_{3}$ groups omitted for clarity. Thermal ellipsoids displayed at $50 \%$ probability level. Selected bond distances $(\AA)$ and angles $\left(^{\circ}\right)$ : Fe-N3 1.982(2), Fe-N4 1.989(2), Fe-C40 2.065(3), C40-Si1 1.831(3), Na-C2 2.551(3), Na-O1 2.348(2), Na-O2 2.32(3), Na-O3 2.307(2), C2-N1 1.365(3), C2-N2 1.363(3); N3-Fe-N4 123.40(10), N3-Fe-C40 119.56(11), N4-Fe-C40 116.84(11), Na-C2-N1 121.30(16), Na-C2-N2 121.30(16), N1-C2-N2 101.9(2), C2-Na-O1 122.69(9), C2-Na-O2 126.5(6), C2-Na-O3 110.69(9), O1-Na-O2 89.5(6), O1-Na-O3 101.60(9), O2-Na-O3 101.3(5).

The ${ }^{1} \mathrm{H}$ NMR spectra of $\mathbf{3}$ and $\mathbf{4}$ in $\mathrm{d}_{8}$-THF (see Supporting Information) show well resolved sets of resonances assignable to the IPr ligands, appearing at almost the same chemical shifts as those found for the free carbene, suggesting that in this ethereal solvent, the sodium centre is solvated by $\mathrm{d}_{8}$-THF molecules rather than by the neutral sterically imposing NHC. In addition, for 3, a broad low frequency resonance is observed at $-2.39 \mathrm{ppm}$, which can be assigned to the HMDS groups bound to the paramagnetic Fe(II) centre. In the case of $\mathbf{4}$ the $\mathrm{SiMe}_{3}$ resonances appear at -3.77 and $7.80 \mathrm{ppm}$ for the HMDS and monosilyl groups respectively. The solution phase magnetic moment of $\mathbf{3}$ and $\mathbf{4}$ (4.90 and $4.40 \mu \mathrm{B}$ respectively) determined using the Evans method are consistent with a high spin $S=2$ configuration.

The formation of coordination products $\mathbf{3}$ and $\mathbf{4}$ in the reactions of sodium ferrates $\mathbf{1}$ and $\mathbf{2}$ with IPr contrasts with our previous findings using a related family of amido-based bimetallic reagents, in particular sodium zincates, which can promote the deprotonation of several unsaturated NHCs at the "abnormal" C4 position of the imidazole ring under mild reaction conditions via a direct zincation process. ${ }^{37}$ Even under harsher reaction conditions, by heating the reaction mixtures at $70^{\circ} \mathrm{C}$ for 12 hours, only adducts 3 and $\mathbf{4}$ were obtained. We next attempted the synthesis of a ferrate complex containing an anionic $\mathrm{NHC}^{38}$ using an 
indirect approach, by treating the three-coordinate NHC complex $\left[(\operatorname{IPr}) \mathrm{Fe}(\mathrm{HMDS})_{2}\right]^{39}$ with either of both sodium reagents, $\mathrm{NaHMDS}$ or $\mathrm{NaCH}_{2} \mathrm{SiMe}_{3}$. Interestingly these reactions also yielded complexes 3 and $\mathbf{4}$ respectively, revealing that under these conditions, not only do the polar sodium reagents fail to metallate IPr but also maintain the preference of the iron(II) bis(amido) fragment to coordinate to another anionic ligand (either $\mathrm{HMDS}$ or $\mathrm{CH}_{2} \mathrm{SiMe}_{3}$ ) rather than to the neutral NHC. Interestingly, similar reactivity has been noted by us for alkylzinc and alkylgallium NHC complexes that when treated with organolithium reagents form the relevant co-complexation lithium ate species, with the NHC ligand coordinated to $\mathrm{Li}^{37,40}$ On the other hand, contrasting with these studies, Robinson has demonstrated that when the free IPr is treated with BuLi the straightforward selective lithiation of the NHC occurs at the $\mathrm{C} 4$ position of the imidazole ring, affording a novel anionic carbene lithium complex. ${ }^{41}$ Inspired by this pioneering metallating work, we first treated IPr in hexane with an equimolar amount of the sodium alkyl $\mathrm{NaCH}_{2} \mathrm{SiMe}_{3}$, leading almost instantaneously to a white solid which was subsequently reacted with one equivalent of $\mathrm{Fe}(\mathrm{HMDS})_{2}$. Introduction of THF afforded a green/brown solution which upon cooling to $-30^{\circ} \mathrm{C}$ deposited green crystals of heteroleptic ferrate (THF) ${ }_{3} \mathrm{Na}\left[: \mathrm{C}\left\{\left[\mathrm{N}\left(2,6-{ }^{i} \operatorname{Pr}_{2} \mathrm{C}_{6} \mathrm{H}_{3}\right)\right]_{2} \mathrm{CHCFe}(\mathrm{HMDS})_{2}\right\}\right]$ (5) in a $60 \%$ yield (Scheme $2 \mathrm{c}$ ).

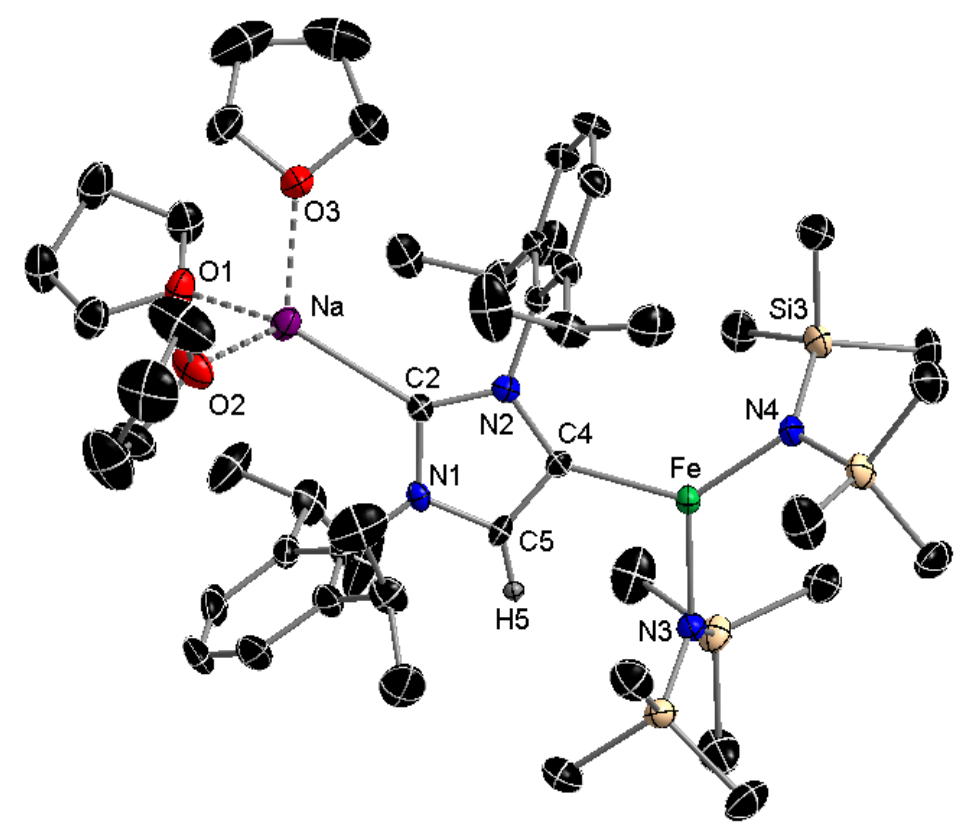

Figure 5 - Molecular structure of complex 5 with selective atom labelling. Hydrogen atoms omitted for clarity. Thermal ellipsoids displayed at 50\% probability level. Selected bond distances $(\AA)$ and angles $\left({ }^{\circ}\right)$ : Fe-C4 2.085(4), Fe-N3 1.998(3), Fe-N4 1.973(3), Na-C2 2.510(4), Na-O1 2.336(3), Na-O2 2.313(3), Na-O3 2.286(3), C2-N1 1.357(4), C2-N2 
1.371(4); C4-Fe-N3 105.15(14), C4-Fe-N4 131.45(14), N3-Fe-N4 123.39(13), Fe-C4-N2 139.3(3), Na-C2-N1 121.3(2), Na-C2-N2 136.9(3), N1-C2-N2 101.7(3).

X-ray crystallographic studies established the contacted ion pair structure of 5 (Figure 5) where the carbene has now been incorporated into the ferrate scaffold acting as an anionic ligand, coordinating through its normal $\mathrm{C} 2$ position to $\mathrm{Na}[\mathrm{Na}-\mathrm{C} 22.510(4) \AA]$, whilst $\mathrm{Fe}$ occupies the position previously filled by an $\mathrm{H}$ atom, bonding to the $\mathrm{C} 4$ position $[\mathrm{Fe}-\mathrm{C} 4$ 2.085(4) $\AA$ ]. Understandably this distance is shorter than that reported for the abnormal complex $\left[(a \mathrm{IPr}) \mathrm{Fe}(\mathrm{HMDS})_{2}\right]^{42}$ which also displays a tricoordinate Fe atom connected to HMDS groups and to the $\mathrm{C} 4$ position of a neutral NHC ligand. In agreement with its anionic

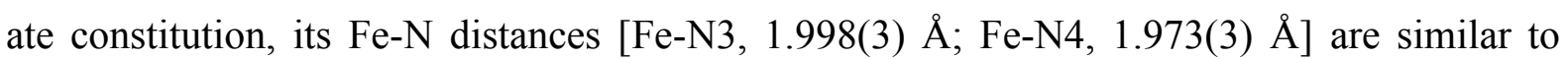
those found for the homoleptic anion of 3 [average Fe-N $1.993 \AA$ ] and slightly elongated to those reported for $\left[(a \mathrm{IPr}) \mathrm{Fe}(\mathrm{HMDS})_{2}\right]^{42}$ [average Fe-N $\left.1.962 \AA\right]$. Comparing the molecular structures of $\mathbf{4}$ and $\mathbf{5}$, it could be tempting to describe $\mathbf{4}$ as a pre-metallation complex of $\mathbf{5}$, however it should be noted that $\mathbf{4}$ is a stable species that does not evolve to $\mathbf{5}$ even under forcing reaction conditions $\left(70^{\circ} \mathrm{C}, 5\right.$ hours $)$ which makes this assumption very unlikely. This highlights the importance of the synthetic methods employed and the remarkable differences that can be realized in bimetallic chemistry by having the two metals operate either in a stepwise or synchronous manner. ${ }^{1}$

The ${ }^{1} \mathrm{H}$ NMR spectrum of 5 in $\mathrm{C}_{6} \mathrm{D}_{6}$ exhibits a series of broad resonances in the range 10.59 to $-6.94 \mathrm{ppm}$, including a signal at $-4.21 \mathrm{ppm}$, which integrating for $36 \mathrm{H}$ can be assigned to the HMDS hydrogen atoms. In addition, another broad low frequency resonance is observed at $-26.37 \mathrm{ppm}$, which has been attributed to the $\mathrm{CH}$ fragment of the imidazolyl ring (see Supporting Information). The complexity and broadness of this NMR spectrum contrast with the relative simplicity and good resolution of the spectra recorded for $\mathbf{3}$ and $\mathbf{4}$, where neutral IPr is not attached to a paramagnetic Fe(II) centre.

The formation of $\mathbf{5}$ can be rationalized in terms of a stepwise indirect ferration process. Initially IPr is deprotonated at its $\mathrm{C} 4$ position by the polar organosodium reagent to form $\mathrm{Na}^{+} \mathrm{IPr}^{-}$, which in turn undergoes transmetallation with the more electronegative iron bis(amide). Although the white powder obtained by reacting IPr with $\mathrm{NaCH}_{2} \mathrm{SiMe}_{3}$ cannot be characterized spectroscopically due to its complete lack of solubility in organic solvents such as THF or toluene, the isolation of $\mathbf{5}$ provides compelling proof that the metallation of the NHC has occurred. ${ }^{43}$ 
C4-deprotonation of unsaturated NHCs constitutes one of the main synthetic routes to access anionic (or ditopic) NHCs. ${ }^{38,44}$ To date, only two efficient metallating reagents have proved capable of selectively abstracting an $\mathrm{H}$ from the imidazole ring of IPr, monometallic ${ }^{n} \mathrm{BuLi}^{41,45}$ and the mixed metal system [(TMEDA)NaZn(TMP) $\left.{ }^{t} \mathrm{Bu}_{2}\right] .{ }^{37,46}$ Our studies show that sodium alkyl $\mathrm{NaCH}_{2} \mathrm{SiMe}_{3}$ can also promote the selective metallation ( $\mathrm{Na}-\mathrm{H}$ exchange) reaction of the imidazole ring at its $\mathrm{C} 4$ position. Related to the synthesis of $\mathbf{5}$, it should be noted that Goicoechea has recently demonstrated the reduction of $\left[\mathrm{Fe}(\mathrm{IPr})(\mathrm{Mes})_{2}\right](\mathrm{Mes}=$ mesityl) with potassium graphite which allows for the isolation of the iron complex $\mathrm{K}\left[\left\{: \mathrm{C}\left[\mathrm{N}\left(2,6-{ }^{i} \mathrm{Pr}_{2} \mathrm{C}_{6} \mathrm{H}_{3}\right)\right]_{2}(\mathrm{CH}) \mathrm{C}\right\}_{2} \mathrm{Fe}(\mathrm{Mes})\right]$ containing two anionic carbenes, both bound through their $\mathrm{C} 4$ position to $\mathrm{Fe}^{47}$ This compound is formed in a $26 \%$ yield as a result of a redistribution process, with the concomitant formation of a tris(mesityl) potassium ferrate and $\mathrm{H}_{2}$.

Abnormal NHC-Fe complex via electrophilic interception. Recent studies in main group chemistry have shown that certain anionic NHC complexes when treated with a suitable electrophile such as $\mathrm{HCl} \bullet \mathrm{NEt}_{3}$ or MeOTf can be transformed into their neutral abnormal adducts, where the imidazole ring of the NHC binds to the metal through its backbone (using its $\mathrm{C} 4$ position). ${ }^{48}$ Although within transition metals, abnormal carbene complexes are more abundant than with $s$ - and $p$-block elements, ${ }^{49}$ the number of Fe complexes containing these ligands is still limited to just a few recent examples. ${ }^{50}$ Some of these studies employ pincer ligands, ${ }^{50 \mathrm{a}}$ whereas Grubbs has used Bertrand's isolable abnormal carbene $(a \mathrm{NHC}=1,3$ bis(2,6-diisopropylphenyl)-2,5-diphenyl-imidazol-4-ylidene $)^{51}$ to trap and stabilize an unique intermediate di-iron cyclo-octatetraenyl (COT) complex. ${ }^{50 \mathrm{~b}}$ More recently, Layfield has reported a thermally induced rearrangement of [IPrFe(HMDS) $\left.)_{2}\right]$ which after 3 hours in refluxing toluene solution evolves to its abnormal isomer [aIPrFe(HMDS $\left.)_{2}\right] .{ }^{42}$ Intrigued by these precedents, we next pondered whether electrophilic interception of anionic NHC complex $\mathbf{5}$ could also allow access to neutral abnormal Fe complexes. Thus, $\mathbf{5}$ was treated with a molar equivalent of MeOTf at $-78^{\circ} \mathrm{C}$ in toluene (Scheme 3). The reaction took place with the formation of a white precipitate (presumably NaOTf) affording neutral abnormal $\mathrm{Fe}$ NHC complex $\left[\mathrm{CH}_{3} \mathrm{C}\left\{\left[\mathrm{N}\left(2,6-i \mathrm{Pr}_{2} \mathrm{C}_{6} \mathrm{H}_{3}\right)\right]_{2} \mathrm{CHCFe}(\mathrm{HMDS})_{2}\right\}\right]$ (6) as a yellow crystalline solid in a $28 \%$ isolated yield. Compound $\mathbf{6}$ is obtained as the result of the selective methylation of the $\mathrm{C} 2$ position of the anionic NHC ligand present in $\mathbf{5}$, leaving its $\mathrm{Fe}-\mathrm{C} 4$ bond and more importantly the Fe-N bonds intact. This is particularly noteworthy as recent studies have shown that the amido groups in the related complex [IPr.Fe(HMDS) $)_{2}$ can display basic lability, metallating substrates such as $\mathrm{PhSeH}$ with the subsequent formation of $\operatorname{HMDS}(\mathrm{H}){ }^{31 \mathrm{c}}$ 


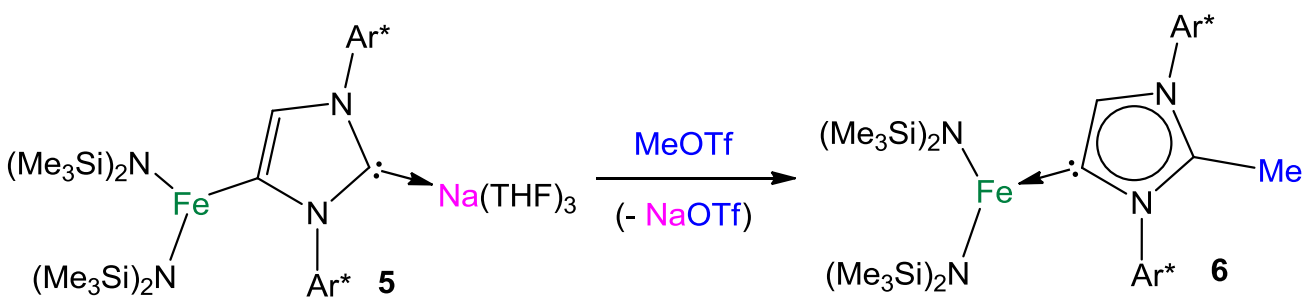

Scheme 3 Electrophilic interception of anionic NHC complex 5 with MeOTf

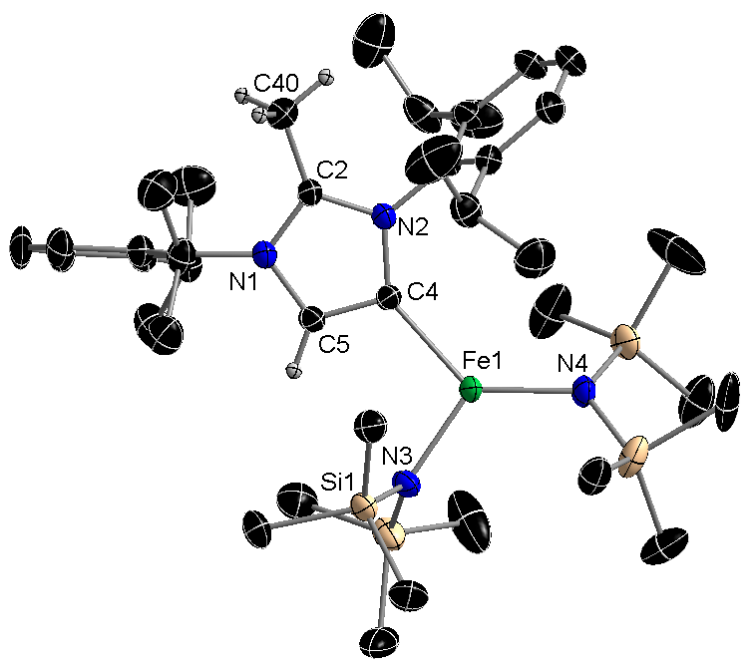

Figure 6 - Molecular structure of complex 6 with selective atom labelling. Hydrogen atoms minor disorder components in $\mathrm{SiMe}^{3}$ groups omitted for clarity. Thermal ellipsoids displayed at 50\% probability level. Selected bond distances $(\AA)$ and angles $\left({ }^{\circ}\right)$ : Fe-C4 2.113(2), Fe-N3 1.9732(19), Fe-N4 1.9459(19), C2-N1 1.330(4), C2-N2 1.341(3), C2-C40 1.491(3); C4-FeN3 104.02(8), C4-Fe-N4 132.84(8), N3-Fe-N4 123.14(8), Fe-C4-N2 140.30(16), C40-C2-N1 125.3(2), C40-C2-N2 126.9(2), N1-C2-N2 107.46(19)

The molecular structure of $\mathbf{6}$ was established by X-ray crystallographic studies (Figure 6). The bond length of 1.491(3) $\AA$ for C2-C40 is consistent with a single bond while the Fe-C4 bond length $[2.113(2) \AA]$ is only slightly elongated with respect to that in the anionic complex $5\left[\begin{array}{ll}2.085(4) & \AA\end{array}\right]$ and almost identical to that reported for $\left[(a \operatorname{IPr}) \mathrm{Fe}(\mathrm{HMDS})_{2}\right]$ $[2.117(2) \AA] .{ }^{42}$ Supporting previous studies that have described abnormal NHC ligands as stronger $\sigma$-donors than their normal isomers, ${ }^{51}$ the Fe-C4 distance in $\mathbf{6}$ is shorter than in the related complex containing a normal NHC ligand [(IPr)Fe(HMDS) 2$][2.182(2) \AA]$ which also features a tricoordinate Fe center. ${ }^{39}$

The ${ }^{1} \mathrm{H}$ NMR spectrum of paramagnetic 6 in $\mathrm{d}_{8}$-toluene features a series of broad resonances in the range of 29.37 to $-33.29 \mathrm{ppm}$. (Supporting Information). A distinctive very broad resonance for the $\mathrm{C} 5$ hydrogen atom on the imidazole ring can be seen at $-33.29 \mathrm{ppm}$, which 
is just slightly upfield to that observed for the same proton in ferrate $\mathbf{5}$ (at $-26.37 \mathrm{ppm}$ ), whilst the resonances for the $\mathrm{CH}_{3}$ group attached to the $\mathrm{C} 2$ atom of the carbene and for these of the HMDS groups appear downfield at 29.36 and $-5.05 \mathrm{ppm}$, respectively. Resonances for the aromatic protons are observed at 10.78, 9.64 and $8.58 \mathrm{ppm}$ whilst the lack of symmetry in the imidazole ring is evidenced by the presence of two distinct sets of signals for the isopropyl substitutes $(\delta=1.32$ and $1.21 \mathrm{ppm}$ for $\mathrm{CH}$ 's and $\delta=4.53,0.98,-3.40$ and -6.96 for Me groups).

\section{Magnetic studies}

The electronic structure of the Fe(II) centres in 1-6 was studied through bulk magnetization measurements. Thus, molar paramagnetic susceptibility $\left(\chi_{\mathrm{M}}\right)$ data were collected on microcrystalline samples in the 2 to $300 \mathrm{~K}$ temperature range, under a constant magnetic field of $0.5 \mathrm{~T}(0.1 \mathrm{~T}$ in the case of 3$)$, in the warming mode. The results are represented in Figure 7 in form of $\chi_{\mathrm{M}} T v s T$ curves. In all cases, the $\chi_{\mathrm{M}} T$ product at $300 \mathrm{~K}$ is slightly higher than the expected value $\left(3.00 \mathrm{~cm}^{3} \mathrm{~K} \mathrm{~mol}^{-1}\right.$ for $\left.g=2.0\right)$ for one uncoupled high-spin ( $\left.S=2\right)$ iron(II) centre $\left(3.67,3.53,3.62,3.39,3.67\right.$ and $3.44 \mathrm{~cm}^{3} \mathrm{~K} \mathrm{~mol}^{-1}$ for $\mathbf{1 - 6}$ respectively) indicating that the ligand field is insufficient to force a violation of Hund's rule. The estimated $g$ values using the Curie Law for the room temperature data are $g=2.21,2.17,2.20,2.13,2.21$ and 2.14 respectively, which suggests the presence of unquenched angular momentum, which in turn is coupled to the electronic spin, thus leading to susceptibility values larger than the calculated for "spin-only" systems. Inspection of the curves reveals that in lowering the temperature from $300 \mathrm{~K}$, a slight increase of $\chi_{\mathrm{M}} T$ takes place for all the compounds, which is attributed to a slight decomposition of the sample occurred upon warming (certainly involving the oxidation to $\mathrm{Fe}(\mathrm{III}))$. In analysing the $\chi_{\mathrm{M}} T$ product below the almost imperceptible maximum (near $260 \mathrm{~K}$ ) a very slightly positive slope is barely appreciable, most likely explained by the influence of a weak temperature-independent contribution to paramagnetism. Sharp decreases are observed for all the products at the lowest temperatures, leading to $\chi_{\mathrm{M}} T$ values of 1.35 , $1.04,1.30,0.97,1.45$ and $1.59 \mathrm{~cm}^{3} \mathrm{~K} \mathrm{~mol}^{-1}$ (for $\mathbf{1 - 6}$ respectively) at $2 \mathrm{~K}$. This very apparent decline is explained by the effect of zero-field splitting (ZFS) which is another consequence of the presence of spin-orbit coupling. The latter is explained by the nature of the electronic states of $\mathrm{Fe}(\mathrm{II})$ in this coordination environment, which in their ground state are expected to lack any orbital angular momentum $(L=0)$ that is however altered by mixing of electronic excited states with non-zero $L$. The effects of this mixing can be modeled using the 
perturbation theory. Thus, the experimental data were fit using the program $\mathrm{PHI}^{52}$ by matrix diagonalization of the (perturbative) anisotropic spin Hamiltonian defined in equation 1:

$\widehat{H}=D\left(\hat{S}_{z}^{2}-\frac{1}{3} \hat{S}^{2}\right)+E\left(\hat{S}_{x}^{2}-\hat{S}_{y}^{2}\right)+\mu_{B} \cdot\left(\hat{S}_{x} g_{x} B_{x}+\hat{S}_{y} g_{y} B_{y}+\hat{S}_{z} g_{z} B_{z}\right)$

In this equation, $D$ and $E$ stand for axial and rhombic ZFS parameters, respectively, $\widehat{S}$ is total spin operator and $\widehat{S}_{l}(i=x, y, z)$ are the operators of its components. $B_{i}(i=x, y, z)$ are the components of the magnetic induction and $\mu_{B}$ is the Bohr magneton. The anisotropy of the $g$ factor was considered by setting $g_{x}=g_{y} \neq g_{z}$, which takes into account the trigonal planar coordination environment around Fe(II). No intermolecular interactions where considered, given the large distance between paramagnetic centers.

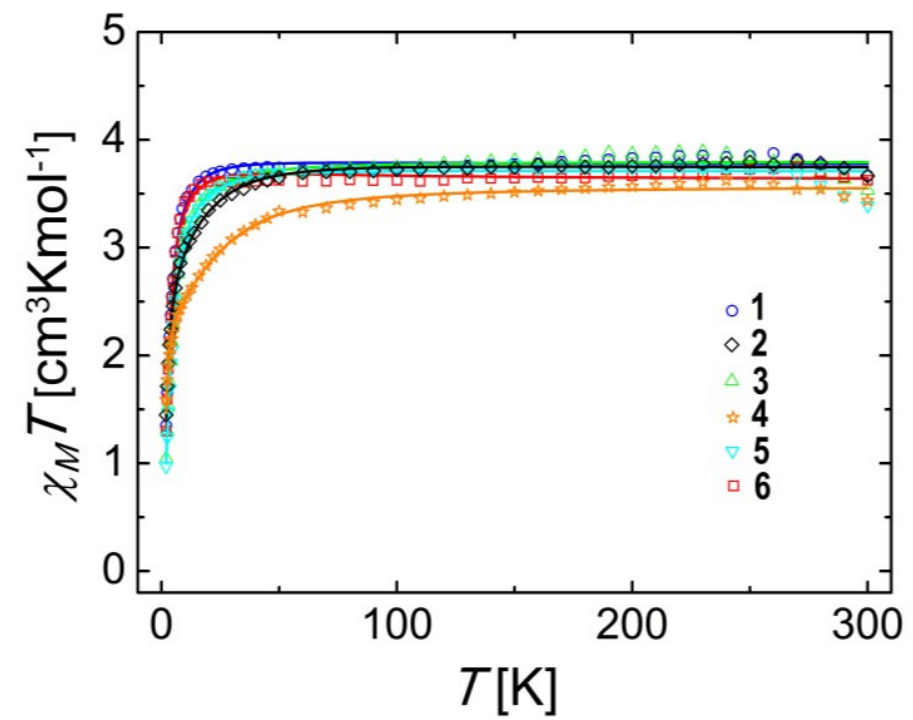

Figure $7 \chi_{\mathrm{M}} T$ vs $T$ curves of compounds 1-6 (measurement setup: $2 \rightarrow 300 \mathrm{~K}$ ): solid lines represent the results of the fits.

The results from the fitting are collected in Table 1. For compounds $\mathbf{1}$ and $\mathbf{3}$, the best fits reveal the presence of axial zero-field splitting ( $D$ values of +7.5 and $+8.3 \mathrm{~cm}^{-1}$, respectively, and $E=0$ ) with anisotropic $g$ values where $g_{\mathrm{x}}=g_{\mathrm{y}}>g_{\mathrm{z}}$. These parameters are in accordance with the consistency criterion derived from perturbation theory defined as $D=0.5 \lambda\left(g_{\mathrm{z}}-\right.$ $\left.g_{\mathrm{x}}\right),{ }^{53}$ taking a value of the spin-orbit coupling parameter $\lambda$ for $\mathrm{Fe}(\mathrm{II})$ close to the that of the free ion $\left(-102 \mathrm{~cm}^{-1}\right) .{ }^{54}$ Quite similar values were previously reported for the related compound $\left[\mathrm{Li}(15 \text {-crown-5) }]^{+}\left[\mathrm{Fe}\left\{\mathrm{N}\left(\mathrm{SiMe}_{3}\right)_{2}\right\}_{3}\right]^{-}\right.$, which exhibits a higher degree of axiality. ${ }^{31 \mathrm{~d}}$ Heteroleptic compounds $\mathbf{2}$ and $\mathbf{4}$ follow almost an identical pattern of behaviour as 
the above systems ( $D$ values of +9.6 and $+10.2 \mathrm{~cm}^{-1}$, respectively, and $E=0$ ). These values of $D$ suggest that replacing one $\left[\mathrm{N}\left(\mathrm{SiMe}_{3}\right)_{2}\right]^{-}$ligand with $\left[\mathrm{CH}_{2} \mathrm{SiMe}_{3}\right]^{-}$does not modify significantly the crystal field around Fe(II) ion, as can be expected bearing in mind the structural and electronic similarity of those ligands. The slightly differing effect on the magnetic properties, can however be interpreted in terms of the different donor character of the ligands (see below).

In contrast to this, the fits for compounds 5 and $\mathbf{6}$ led to negative $D$ values $(-15.5$ and -17.7 $\mathrm{cm}^{-1}$, respectively) with the appearance of a rhombic zero-field splitting parameter, $E( \pm 4.2$ and $\left.\pm 0.7 \mathrm{~cm}^{-1}\right)$. The latter is the natural consequence of the deviation from the idealized trigonal environment around the metal ion resulting from the presence of NHC ligands, which introduce a new interaction with the metal $d$ orbitals due to $\pi$ donating character of the heterocycles. In fact, this not only generates rhombicity but changes the sign of the anisotropy, turning axial instead of easy plane. A drastic change in anisotropy of $3 d$ metals as a result of changes to the $\pi$-donor properties of ligands as observed here, has been previously predicted theoretically. ${ }^{56}$ The anisotropy to the $g$ factor (Table 1) is featured in these fits by components not differing significantly but leading to two qualitative distinct behaviors; for of 6, $g_{x}=g_{y}>g_{z}$ while for $\mathbf{5} g_{z}>g_{x}=g_{y}$. This means that $\mathbf{6}$ does not comply with the above mentioned criterion, which could be explained by the presence of strong spin-orbit coupling interactions. The latter weakens the accuracy of the perturbative model assumed with the spin Hamiltonian of Eq. 1. In any case, the observations are perfectly in line with the behaviour revealed by other complexes of the $\left[\mathrm{Fe}(\mathrm{HMDS})_{2} \mathrm{~L}\right]$ type (where $\mathrm{L}=$ neutral ligand such as $\mathrm{PCy}_{3}, \mathrm{THF}$ or IPr) previously reported, all exhibiting negative $D$ parameters and moderate $E$ values that can be fine-tuned by changing the substituents on the ligands employed (see Table S2 in Supporting Information for details). ${ }^{10 \mathrm{~g}, 31 \mathrm{~d}, 39,55}$ On the other hand, the important effect to the anisotropy caused by the $\pi$ bonding character of the NHC donors present in $\mathbf{5}$ and $\mathbf{6}$ is very significant and, to the best of our knowledge, it is revealed here for the first time. The gradation of $D$ is also reflected in the values of $\chi_{\mathrm{M}} T$ at low temperatures, which follow the ordering $\left\{\mathrm{Fe}(\mathrm{HMDS})_{2} \mathrm{CH}_{2} \mathrm{SiMe}_{3}\right\}^{-} \approx\left\{\mathrm{NaFe}(\mathrm{HMDS})_{2} \mathrm{CH}_{2} \mathrm{SiMe}_{3}\right\}<\left\{\mathrm{Fe}(\mathrm{HMDS})_{3}\right\}^{-} \approx$ $\left[\left\{\mathrm{NaFe}(\mathrm{HMDS})_{3}\right\}_{\infty}\right]<(\mathrm{THF})_{3} \mathrm{Na}\left[: \mathrm{C}\left\{\left[\mathrm{N}\left(2,6-{ }^{i} \mathrm{Pr}_{2} \mathrm{C}_{6} \mathrm{H}_{3}\right)\right]_{2} \mathrm{CHCFe}(\mathrm{HMDS})_{2}\right\}\right]<\left[\mathrm{CH}_{3} \mathrm{C}\{[\mathrm{N}(2,6-\right.$ $\left.\left.\left.i \operatorname{Pr}_{2} \mathrm{C}_{6} \mathrm{H}_{3}\right)\right]_{2} \mathrm{CHCFe}(\mathrm{HMDS})_{2}\right\}$ ]. The negative $D$ parameter values for 5 and $\mathbf{6}$ are consistent with this (which imply population of states with higher angular momenta at lower temperatures). For the other complexes, this is a consequence of the stronger $\sigma$-donor character of the carbanion over the amido ligand, which, for a positive $D$ parameter, implies a larger population of the diamagnetic ground state at lower temperatures. 
Table 1. Fitting parameters for compounds 1-6

\begin{tabular}{|c|c|c|c|c|c|c|c|}
\hline Complex & $\chi_{\mathrm{M}} T^{u}$ at r.t. $(g)$ & $\mu_{e f f}^{b}$ at r.t & $\chi_{\mathrm{M}} T^{u}$ at $2 \mathrm{~K}$ & $g_{x}=g_{y}$ & $g_{\mathrm{z}}$ & $D\left(\mathrm{~cm}^{-1}\right)$ & $E\left(\mathrm{~cm}^{-1}\right)$ \\
\hline 1 & $3.67(2.21)$ & 5.42 & 1.35 & 2.30 & 2.12 & 7.5 & 0.0 \\
\hline 2 & $3.53(2.17)$ & 5.32 & 1.04 & 2.23 & 2.28 & 9.6 & 0.0 \\
\hline 3 & $3.62(2.20)$ & 5.38 & 1.30 & 2.30 & 1.97 & 8.3 & 0.0 \\
\hline 4 & $3.39(2.13)$ & 5.21 & 0.97 & 2.26 & 2.15 & 10.2 & \pm 0.1 \\
\hline 5 & $3.67(2.21)$ & 5.42 & 1.45 & 2.17 & 2.35 & -15.5 & \pm 4.2 \\
\hline 6 & $3.44(2.14)$ & 5.25 & 1.59 & 2.21 & 2.12 & -17.7 & \pm 0.7 \\
\hline
\end{tabular}

${ }^{a} \mathrm{~cm}^{3} \mathrm{Kmol}^{-1},{ }^{b}$ Bohr magneton.

\section{Conclusions}

The new solvent-free sodium ferrates $\mathbf{1}$ and $\mathbf{2}$ have been synthesized straightforwardly by cocomplexation of $\mathrm{Fe}(\mathrm{HMDS})_{2}$ with the sodium reagents $\mathrm{Na}$ (HMDS) and $\mathrm{NaCH}_{2} \mathrm{SiMe}_{3}$ respectively. The complicated polymeric arrangements of $\mathbf{1}$ and $\mathbf{2}$ can be broken down by introducing unsaturated carbene IPr to form the discrete NHC-separated ion pair ferrate $\mathbf{3}$ and partially NHC-separated (THF is also needed) ion pair 4 respectively. In these complexes the IPr neutral donor coordinates preferentially to the Na atom, while more Lewis acidic $\mathrm{Fe}$ is coordinated exclusively to anionic ligand sets. Interestingly, $\mathbf{3}$ and $\mathbf{4}$ were also obtained when the NHC complex [IPrFe(HMDS) $)_{2}$ was treated with $\mathrm{Na}(\mathrm{HMDS})$ and $\mathrm{NaCH}_{2} \mathrm{SiMe}_{3}$ respectively. Contrastingly, sequentially reacting IPr with $\mathrm{NaCH}_{2} \mathrm{SiMe}_{3}$ then $\mathrm{Fe}(\mathrm{HMDS})_{2}$ allows the isolation of heteroleptic ferrate 5 where both metals are connected by an anionic NHC. Compound $\mathbf{5}$ can be envisaged as a product of an indirect ferration process, where IPr is first metallated (sodiated) by the polar sodium reagent which in turn undergoes fast transmetallation with $\mathrm{Fe}(\mathrm{HMDS})_{2}$. Collectively these findings illustrate the significantly different outcomes that are possible in mixed-metal chemistry, when the synergy created by two metals operates simultaneously in the one molecule or in a stepwise manner in two molecules. Unveiling a new approach in transition-metal chemistry, treatment of $\mathbf{5}$ with equimolar amounts of MeOTf led to the isolation of the tricoordinate neutral iron abnormal NHC complex 6 together with NaOTf. Studies probing the magnetic susceptibility properties of 1-6 have revealed an important change to their anisotropy by replacing a pure $\sigma$-donor from an idealized trigonal coordination environment (1-4) by an NHC that can offer $\pi$ donating character (5 and 6). 


\section{EXPERIMENTAL SECTION}

Full experimental details and characterization of compounds 1-6 are included in the Supporting Information.

Supporting Information available: CIF files giving crystallographic results and full experimental details are available free of charge via the internet http://pubs.acs.org.

Acknowledgments We thank the EPSRC and European Research Council (ERC) for their generous sponsorship of this research. GA thanks Spanish MINECO (CTQ2012-32247) and IB thanks the Generalitat de Catalunya for a PhD grant (FI-DGR 2014).

\section{References}

(1) (a) Mulvey, R. E.; Robertson, S. D. Top. Organomet. Chem. 2014, 47, 129-158. (b) Uchiyama, M.; Wang, C. Top. Organomet. Chem. 2014, 47, 159-202.

(2) For recent authoritative reviews in the area see: (a) Mulvey, R. E. Dalton Trans. 2013, 42, 6676-6693. (b) Mongin, F.; Marchand, A. M. Chem. Rev. 2013, 113, 7563-7727. (c) Tilly, D.; Chevallier, F.; Mongin, F.; Gross, P. C. Chem. Rev. 2014, 114, 1207-1257. (d) Klatt, T.; Markiewicz, J. T.; Sämann, C.; Knochel, P. J. Org. Chem. 2014, 79, 42534269 .

(3) For selected references see: (a) Blair, V. L.; Kennedy, A. R.; Mulvey, R. E.; O'Hara, C. T. Chem. Eur. J. 2010, 16, 8600-8604. (b) Baillie, S. E.; Blair, V. L.; Blakemore, D. C.; Hay, D.; Kennedy, A. R.; Pryde, D. C.; Hevia, E. Chem. Commun. 2012, 48, 1985-1987. (c) Martínez-Martínez, A. J.; Armstrong, D. R.; Conway, B.; Fleming, B. J.; Klett, J.; Kennedy, A. R.; Mulvey, R. E.; Robertson, S. D.; O'Hara, C. T. Chem. Sci. 2014, 5, 771781. (d) Armstrong, D. R.; Garden, J. A.; Kennedy, A. R.; Leenhouts, S. M.; Mulvey, R. E.; O'Keefe, P.; O'Hara, C. T.; Steven, A. Chem. Eur. J. 2013, 19, 13492-13503. (e) Baillie, S. E.; Bluemke, T. D.; Clegg, W.; Kennedy, A. R.; Klett, J.; Russo, L.; de Tullio, M.; Hevia, E. Chem. Commun. 2014, 50, 12859-12862. (f) Clegg, W.; Crosbie, E.; DaleBlack, S. H.; Hevia, E.; Honeyman, G. W.; Kennedy, A. R.; Mulvey, R. E.; Ramsay, D. L.; Robertson, S. D. Organometallics 2015, 34, 2580-2589.

(4) Martínez-Martínez, A. J.; Kennedy, A. R.; Mulvey, R. E.; O'Hara, C. T. Science 2014, $346,6211,834-837$.

(5) (a) Alborés, P.; Carrella, L. M.; Clegg, W.; García-Alvarez, P.; Kennedy, A. R.; Klett, J.; Mulvey, R. E.; Rentschler, E.; Russo, L. Angew. Chem. Int. Ed. 2009, 48, 3317-3321. (b) 
Blair, V. L.; Carrella, L. M.; Clegg, W.; Conway, B.; Harrington, R. W.; Hogg, L. M.; Klett, J.; Mulvey, R. E.; Rentschler, E.; Russo, L. Angew. Chem. Int. Ed. 2008, 47, 62086211. (c) Blair, V. L.; Carrella, L. M.; Clegg, W.; Klett, J.; Mulvey, R. E.; Rentschler, E.; Russo, L. Chem. Eur. J. 2009, 15, 856-863.

(6) Wunderlich, S. H.; Knochel, P. Angew. Chem. Int. Ed. 2008, 48, 9717-9720.

(7) Nagaradja, E.; Chevallier, F.; Roisnel, T.; Jouikov, V.; Mongin, F. Tetrahedron 2012, 68, 3063-3073.

(8) Bedford, R. B.; Brenner. P. B.; Carter, E.; Cogswell, P. M.; Haddow, M. F.; Harvey, J. N.; Murphy, D. M.; Nunn, J.; Woodall, C. H. Angew. Chem. Int. Ed. 2014, 53, 18041808 .

(9) (a) Sherry, B. D.; Fürstner, A. Acc. Chem. Res. 2008, 41, 1500-1511. (b) Bedford, R. B. Acc. Chem. Res. 2015, 48, 1485-1493. (c) Plietker, B. (Ed.) Iron Catalysis in Organic Chemistry; Wiley-VCH: Weinheim, Germany, 2008. (d) Bedford, R. B.; Brenner, P. B. Top. Organomet. Chem. 2015, DOI: 10.1007/3418_2015_99.

(10) See for example: (a) Scott, J.; Gambarotta, S.; Korobkov, I.; Budzelaar, P. H. M. J. Am. Chem. Soc. 2005, 127, 13019-13029. (b) Scott, J.; Gambarotta, S.; Korobkov, I.; Budzelaar, P. H. M. Organometallics 2005, 24, 6298-6300. (c) Fürstner, A.; Martin, R.; Krause, H.; Seidel, G. Goddard, R. Lehmann, C. W. J. Am. Chem. Soc. 2008, 130, 8773-8787. (d) Berges Serrano, C.; Less, R. J.; McPartlin, M.; Naseri, V.; Wright, D. S. Organometallics 2010, 29, 5754-5756. (e) Fürstner, A.; Krause, H.; Lehmann, C. W. Angew. Chem. Int. Ed. 2006, 45, 440-444. (f) Werncke, C. G.; Bunting, P. C.; Duhayon, C.; Long, J. R.; Bontemps, S.; Sabo-Etienne, S. Angew. Chem. Int. Ed. 2015, 54, 245248. (g) Köning, S. N.; Schneider, D.; Maichle-Mössmer, C.; Day, B. M.; Layfield, R. A.; Anwander, R. Eur. J. Inorg. Chem. 2014, 4302-4309.

(11) (a) Ingleson, M. J.; Layfield, R. A. Chem. Commun. 2012, 48, 3579-3589. (b) Bézier, D.; Sortais, J. B.; Darcel, C. Adv. Synth. Catal. 2013, 355, 19-33. (c) Riener, K.; Haslinger, S.; Raba, A.; Högerl, M. P.; Cokoja, M.; Hermann, W. A.; Kühn, F. Chem. Rev. 2014, $114,5215-5272$.

(12) Selected references: (a) Bedford, R. B.; Betham, M.; Bruce, D. W.; Danopoulos, A. A.; Frost, R. M.; Hird, M. J. Org. Chem. 2006, 71, 1104-1110. (b) Ghorai, S. K.; Jin, M.; Hatakeyama, T.; Nakamura, M. Org. Lett. 2012, 14, 1066-1069. (c) Agrawal, T.; Cook, S. P. Org. Lett. 2013, 15, 96-99. (d) Cramer, S. A.; Jenkins, D. M. J. Am. Chem. Soc. 2011, 133, 19342-19345. (e) Dieskau, A. P.; Holzwarth, M. S.; Plietker, B. Chem. Eur. J. 2012, 18, 2423-2429. 
(13) Ohki, Y.; Hatanaka, T.; Tatsumi, K. J. Am. Chem. Soc. 2008, 130, 17174-17186

(14)For selected references see: (a) Danopoulos, A. A.; Braunstein, P.; Stylianides, N.; Wesolek, M. Organometallics 2011, 30, 6514-6517. (b) Liu, Y.; Luo, L.; Xiao, J.; Wang, L.; Song, Y.; Qu, J.; Luo, Y.; Deng. L. Inorg. Chem. 2015, 54, 4752-4760. (c) Ouyang, Z.; Deng, L. Organometallics 2013, 32, 7268-7271. (d) Hashimoto, T.; Urban, S.; Hoshino, R.; Ohki, Y.; Tatsumi, T.; Glorius, F. Organometallics 2012, 31, 4474-4479. (e) Przyojski, J. A.; Arman, H. D.; Tonzetich, Z. J. Organometallics 2012, 31, 32643271. (f) Wu, J.; Dai, W.; Farnaby, J. H.; Hazari, N.; Le Roy, J. J.; Mereacre, V.; Murugesu, M.; Powell, A. K.; Takase, M. K. Dalton Trans 2013, 42, 7404-7413.

(15)(a) Baillie, S. E.; Clegg, W.; García-Álvarez, P.; Hevia, E.; Kennedy, A. R.; Klett, J.; Russo, L. Organometallics 2012, 31, 5131-5142. (b) Armstrong, D. R.; Emerson, H. S.; Hernán-Gómez, A.; Kennedy, A. R.; Hevia, E. Dalton Trans. 2014, 43, 14229-14238.

(16) Recently, this co-complexation method has also been applied to the synthesis of a range of divalent transition-metal HMDS-ate complexes $(\mathrm{M}=\mathrm{Mn}, \mathrm{Fe}$, and $\mathrm{Co})$, including solvent-free lithium ferrate $\left[\mathrm{LiFe}(\mathrm{HMDS})_{3}\right]$, see reference $10 \mathrm{~g}$.

(17) (a) Andersen, R. A.; Faegri Jr., K.; Green, J. C.; Haaland, A. Lappert, M. F.; Leung, W. P.; Rypdal, K. Inorg. Chem. 1988, 27, 1782-1786. (b) Fe(HMDS) $)_{2}$ exhibits a dimeric arrangement in the solid state with three-coordinate Fe centers, see : Olmstead, M. M.; Power, P. P; Shoner, S. C. Inorg. Chem. 1991, 30, 2547-2551.

(18)Baillie, S. E.; Clegg, W.; García-Álvarez, P.; Hevia, E.; Kennedy, A. R.; Klett, J.; Russo L. Chem. Commun. 2011, 47, 388-390.

(19) The same monomeric motif has been previously described for solvent-free lithium magnesiate analog [LiMg(HMDS)3], see: Kennedy, A. R.; Mulvey, R. E.; Rowlings, R. B. J. Am. Chem. Soc. 1998, 120, 7816-7824.

(20) (a) Armstrong, D. R.; Brammer, E.; Cadenbach, T.; Hevia, E.; Kennedy, A. R. Organometallics 2013, 32, 480-489. (b) Armstrong, D. R.; Herd, E.; Graham, D. V.; Hevia, E.; Kennedy, A. R.; Clegg, W.; Russo, L. Dalton Trans. 2008, 1323-1330. (c) Francos, J.; Fleming, B. J.; García-Álvarez, P.; Kennedy, A. R.; Reilly, K.; Robertson, G. M.; Robertson; S. D.; O'Hara, C. T. Dalton Trans. 2014, 43, 14424-14431.

(21)For other examples of donor-free s-block tris(HMDS)-ate complexes see reference 19 and: Kennedy, A. R.; Mulvey, R. E.; Rowlings, R. B. J. Organomet. Chem. 2002, 648, 288-292.

(22) Magraf, G.; Schödel, F.; Sänger, I; Bolte, M.; Wagner, M.; Lerner, H. W. Z. Naturforsch. 2012, 67b, 549-556. 
(23) Sum of the internal angles around $\mathrm{Fe}$ in $\mathbf{1}$ is $359.97^{\circ}$, ranging from $110.48(10)$ to $124.93(10)^{\circ}$.

(24) Avent, A. G.; Antolini, F.; Hitchcock, P. B.; Khvostov, A. V.; Lappert, M. F.; Protchenko, A. V. Dalton Trans. 2006, 919-927.

(25) An even major deviation of these values is observed when comparing 1 with solvent-free trimeric amide $\left[\{\mathrm{Na}(\mathrm{HMDS})\}_{3}\right]$, (mean $\mathrm{Na}-\mathrm{N}$ bond distance: $2.381 \AA$; mean $\mathrm{NNaN}$ bond angle: $139.7^{\circ}$ ), see: Driess, M.; Pritzkow, H.; Skipinski, M.; Winkler, U. Organometallics, 1997, 16, 5108-5112.

(26) The concept of anchoring/ancillary bonding in heterobimetallic chemistry has previously been introduced in the literature by Mulvey, see: Mulvey, R. E. Chem. Commun. 2001, 1049-1056.

(27)Kennedy, A. R.; Klett, J.; Mulvey, R. E.; Newton, S.; Wright, D. S. Chem. Commun. 2008, 308-310.

(28) For other examples in alkali-metal manganate and ferrate chemistry see references $5 \mathrm{c}$ and $11 \mathrm{~g}$.

(29) This value compares well with those found in monomeric sodium ferrate [(TMEDA) NaFe(TMP) $\left.\left(\mathrm{CH}_{2} \mathrm{SiMe}_{3}\right)_{2}\right]$ (mean $\mathrm{Fe}-\mathrm{C}$ bond length, $2.086 \AA$ ) or iron(II) alkyl [(TMEDA)Fe( $\left(\mathrm{CH}_{2} \mathrm{SiMe}_{3}\right)_{2}$ ] (mean $\mathrm{Fe}-\mathrm{C}$ bond length, $2.078 \AA$ ), see reference 5c for details.

(30) Evans, D. F. J. Chem. Soc. 1959, 2003-2005.

(31) This electronic configuration is in line with those reported in the literature for other trigonal planar Fe(II) complexes, for selected references see: (a) Andres, H.; Bominaar, E. L.; Smith, J. M.; Eckert, N. A.; Holland, P. L.; Münck, E. J. Am. Chem. Soc. 2002, 124, 3012-3025. (b) Holland, P. L. Acc. Chem. Res. 2008, 41, 905-914. (c) Pugh, T.; Layfield, R. A. Dalton Trans. 2014, 43, 4251-4254. (d) Eichhöfer, A.; Lan, Y.; Mereacre, V.; Bodenstein, T.; Weigend, F. Inorg. Chem. 2014, 53, 1962-1974. (e) Fillman, K. L.; Przyojski, J. A.; Al-Afyouni, M. H.; Tonzetich, Z. J.; Neidig, M. L. Chem. Sci. 2015, 6, 1178-1188.

(32) This chemical shift appears in the same region as $\mathrm{SiMe}_{3}$ resonances of [\{(-)spartaine $\left.\} \mathrm{Fe}\left(\mathrm{CH}_{2} \mathrm{SiMe}_{3}\right)_{2}\right](\delta=10.14$ and $15.71 \mathrm{ppm})$, see: Bart, S. C.; Hawrelak, E. J.; Schmisseur, A. K.; Lobkovsky, E.; Chirik, P. J. Organometallics, 2004, 23, 237-246.

(33) Attempts to measure the solution magnetic moment of 2 using the Evans method proved unsuccessful due to irreproducible chemical shift differences between the internal reference sample and residual protic solvent producing exceedingly large $\mu_{\text {eff }}$ values. The 
solution-phase effective moment of compounds 3-6 was determined by the Evans methods, finding in all cases values that are consistent with a high spin $S=2$ electronic configuration, see Supporting Information for details.

(34) Hursthouse, M. B; Rodesiler, P. F. Dalton Trans. 1972, 2100-2102.

(35) Putzer, M. A.; Neumüller, B.; Dehnicke, K.; Magull, J. Chem. Ber. 1996, 129, 715-719.

(36) Hill, M. S.; Kociok-Köhn, G.; MacDougall, D. J. Inorg. Chem. 2011, 50, 5234-5241.

(37) Armstrong, D. R.; Baillie, S. E.; Blair, V. L.; Chabloz, N. G.; Diez, J.; Garcia-Alvarez, J.; Kennedy, A. R.; Robertson, S. D.; Hevia, E. Chem. Sci. 2013, 4, 4259-4266.

(38)For an insightful up-to-date review on anionic (or ditopic) NHCs see: Waters, J. B.; Goicoechea, J. M. Coord. Chem. Rev. 2015, 293-294, 80-94.

(39)Layfield, R. A.; McDouall, J. J.; Scheer, M.; Schwarzmaier, C.; Tuna, F. Chem. Commun. 2011, 47, 10623-10625.

(40)Uzelac, M.; Hernan-Gomez, A.; Armstrong, D. R.; Kennedy, A. R.; Hevia, E. Chem. Sci. 2015, doi:10.1039/C5SC02086G.

(41)Wang, Y.; Xie, Y.; Abraham, M. Y.; Wei, P.; Schaefer, H. F.; Schleyer, P. v R.; Robinson, G. H. J. Am. Chem. Soc. 2010, 132, 14370-14372.

(42)Day, B. M.; Pugh, T.; Hendriks, D.; Guerra, C. F.; Evans, D. J.; Bickelhaupt, F. M.; Layfield, R. A. J. Am. Chem. Soc. 2013, 135, 13338-13341.

(43) Significantly, on its own Fe(HMDS $)_{2}$ cannot metallate IPr, instead it forms the adduct $\left[\mathrm{IPrFe}(\mathrm{HMDS})_{2}\right]$ see reference 39.

(44)For a recent example of lateral lithiation of an NHC see: Danopoulos, A. A.; Braunstein, P.; Rezabalc, E.; Frison, G. Chem. Commun. 2015, 51, 3049-3052.

(45)El-Hellani, A.; Lavallo, V. Angew. Chem. Int. Ed. 2014, 53, 4489-4493.

(46) Arnold et al have described the isolation of a bimetallic potassium/yttrium anionic Nheterocyclic dicarbene complex resulting from the reduction of an yttrium NHC complex with potassium naphthalenide, which is formally a deprotonation product. Arnold, P. L.; Liddle, S. T. Organometallics 2006, 25, 1485-1491.

(47) Musgrave, R. A.; Turbervill, R. S. P.; Irwin, M.; Herchel, R.; Goicoechea, J. M. Dalton Trans. 2014, 43, 4335-4344.

(48)(a) Wang, Y.; Xie, Y.; Abraham, M. Y.; Gilliard, R. J.; Wei, P.; Campana, C. F.; Schaefer, H. F.; Schleyer, P. v. R.; Robinson, G. H. Angew. Chem. Int. Ed. 2012, 51, 10173-10176. (b) Wang, Y.; Abraham, M. Y.; Gilliard Jr., R. G.; Wei, P.; Smith, J. C.; Robinson, G. H. Organometallics 2012, 31, 791-796. 
(49)(a) Arnold, P. L.; Pearson, S. Coord. Chem. Rev. 2007, 251, 596-609. (b) Schuster, O.; Yang, L.; Raubenheimer, H. G.; Albrecht, M. Chem. Rev. 2009, 109, 3445-3478. (c) Crabtree, R. H. Coord. Chem. Rev. 2013, 257, 755-766.

(50) See references 31d, 42 and: (a) Danopoulos, A. A.; Tsoureas, N.; Wright, J. A.; Light, M. E. Organometallics 2004, 23, 166-168. (b) Lavallo, V.; El-Batta, A.; Bertrand, G.; Grubbs, R. H. Angew. Chem. Int. Ed. 2011, 50, 268-271.

(51) Aldeco-Perez, E.; Rosenthal, A. J.; Donnadieu, B.; Parameswaran, P.; Frenking, G.; Bertrand, G. Science 2009, 326, 556-559.

(52)Chilton, N. F.; Anderson, R. P.; Turner, L. D.; Soncini A.; Murray, K. S. J. Comput. Chem. 2013, 34, 1164-1175.

(53) Boča, R. Coord. Chem. Rev. 2004, 248, 757-815.

(54) Bendix, J.; Brorson, M.; Schäffer, C. E. Inorg. Chem. 1993, 32, 2838-2849.

(55)Lin, P.-H.; Smythe, N. C.; Gorelsky, S. I.; Maguire, S.; Henson, N. J.; Korobkov, I.; Scott, B. L.; Gordon, J- C.; Baker, R. T.; Murugesu, M. J. Am. Chem. Soc. 2011, 133, 15806-15809.

(56) Goswami, T.; Misra, A. J. Phys. Chem. A., 2012, 116, 5207-5215. 


\section{Text for TOC}

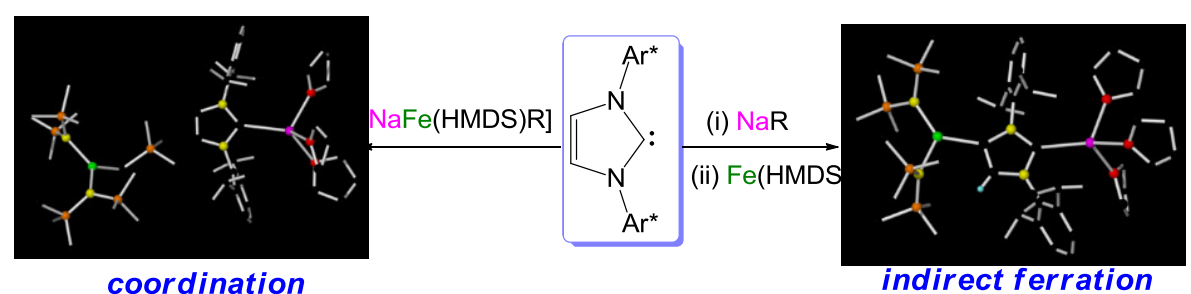

By comparing two alternative bimetallic approaches, two different types of sodium ferrate complexes have been realized. Reaction of NHC IPr with mixed $\mathrm{Na} / \mathrm{Fe}$ bimetallic compounds, gives donor-acceptor coordination products. Contrastingly, illustrating how metal pairs can also work in an stepwise synergistic manner, sequential treatment of IPr with a sodium alkyl followed by the addition of an iron bis(amide) affords a novel ferrate containing a anionic NHC ligand, resulting from an indirect ferration of process. 